\title{
The Effect of High Intensity Interval Training During Eight Weeks on Speed, Agility, and Acceleration in U19 Soccer Players
}

\author{
KADIR GÖKKURT ${ }^{1}$, ALI OSMAN KIVRAK ${ }^{1}$ \\ ${ }^{1}$ Selçuk University, Faculty of Sports Science, Konya, Turkey \\ Correspondence to Ali Osman Kıvrak, Email.aokivrak@selcuk.edu.tr, Cell: 05057382670
}

\begin{abstract}
Aim: The aim in this study was to examine the impact of eight-week high-Intensity interval training on speed, agility, and acceleration under 19 (U19) soccer players.

Materials and methods: Healthy 22 soccer players from Anadolu Selçukspor U19 football team, one of the 2nd League teams of Turkish Football Federation (TFF), participated voluntarily in this study. The soccer players taking part in the study were separated randomly into two as the experimental and control groups. It was determined that the age average of the players constituting the experimental group was 18.36 \pm 0.51 years, their height average was $1.77 \pm 0.06 \mathrm{~m}$, and their body weight average was $71.76 \pm 6.52 \mathrm{~kg}$ while the control group's age average was $17.55 \pm 0.69$ years, height average was $1.76 \pm 0.04 \mathrm{~m}$, and body weight average was $70.85 \pm 5.40 \mathrm{~kg}$. In the study, the soccer players forming the experimental group attended a high-intensity interval training program three days a week for eight weeks, in addition to their regular training. The players of the control group continued their normal training schedule. The soccer players taking part in the study are the players who practice five days a week and play one official match.

Results: In this study, through the comparison of the values of the pre-test and post-test regarding the speed and acceleration property of the soccer players of the experimental group, it was found that their post-test values were better $(p<0.05)$. In terms of their agility property, an improvement of pro-rata 0.008 was seen in the experimental group, while the improvement of the control group took place at the proportion of $0.004(p<0.05)$.

Conclusion: It has been observed that 8-week high-intensity interval training is statistically significant in the speed and acceleration of soccer players. We contemplate that the inclusion of the high-intensity interval training within the annual training schedule in the field of soccer will affect the performance of the soccer players during the season more positively.

Keywords: Agility, Soccer; Interval Training, Acceleration, Speed
\end{abstract}

\section{INTRODUCTION}

Sports science researchers, conditioners and trainers are constantly in search of new training methods that will improve the performance of their athletes and the healthrelated parameters of sedentary persons ${ }^{1}$.

Considering the problems encountered by athletes and trainers who are engaged in sports at professional level, both in preparation and in the competition phase, the physical condition cannot be increased to the desired level or the captured level cannot be maintained for a long time, as well as the injuries that occur in training and competitions and the negativities encountered in the recovery process of these injuries ${ }^{2}$.

Performance in soccer develops depending on many factors such as technique, speed, agility, endurance, coordination tactical, mental, and physiological areas and so on. These factors include the structure and rules of the game, the level of development of the players specific to the branch, the league levels the players, their style of play, the places they play, and the environmental conditions ${ }^{3}$

Soccer players often have to generate, maintain, and repeatedly apply high amounts of power (short explosive sprints, jumps, etc.), provided they only use recovery periods of a few seconds ${ }^{4}$. For this reason, soccer players train in significant amounts to improve their physical capacity $5,6,7$

For success in soccer, running endurance performance is important, but explosive-type efforts such as sprints, jumps, strength, agility, turns, deceptive movements, shooting, and speed are also important ${ }^{8}$.

Average training intensity during the soccer match is stated to be close to the anaerobic threshold or around 80 $90 \%$ of the maximal heart rate. Increased exercise intensity results in the buildup of lactic acid in the blood and muscle. The accumulation of lactic acid in the blood and muscle causes the athlete to tire. This is a factor that negatively affects the performance of the players. During this time, the ability of players to perform repetitive movements with the same quality is closely related to their improved endurance capacities. Endurance capacity in soccer is shaped by three different elements and these three elements are expressed as VO2 max, Anaerobic Threshold and Running Economy ${ }^{9}$.

The basic structure of traditional training in soccer is focused on interval training. The repetition method is also used in traditional speed trainings. Speed, agility and starting speed training is seen as an effective way to improve physical condition in a sport with interval training such as soccer ${ }^{10}$. The characteristic feature of interval training is the systematic change of working and resting or high and low load cycles ${ }^{11}$. Compared to ongoing aerobic exercises, the high-intensity interval training method has attracted great attention because it is efficient in a short time and increases anaerobic capacity together with aerobic capacity ${ }^{12}$.

The Effect of High Intensity Interval Training During Eight Week on Speed, Agility, and Acceleration in U19 Soccer Players 
Physically, speed is the distance traveled within a certain time unit. Speed in training theory is to move a part or all of the body at great speed with the help of members. In other words, it is the highest speed reached by the athlete at a certain distance ${ }^{13}$. Agility is defined as the ability to change direction, slow down and accelerate in a fast and balanced way ${ }^{14}$. Although the aerobic energy system is used intensively in soccer, it is a team sport that requires anaerobic capacity components such as speed, agility, and acceleration in the game ${ }^{15}$. Acceleration is the rate of change in speed that enables the player to reach maximum speed within a minimum amount of time. The maximum speed is the maximum speed a player can run. For the success of the athletes, it is important to reach the maximum running speed and accelerate effectively 16 .

Although the aerobic energy system is used intensively in soccer, it is a team sport that requires anaerobic capacity components such as speed, agility, and acceleration in the game ${ }^{15}$. The ability of the nervous musculature to resist a resistance with a severe contraction is defined as the anaerobic power ${ }^{17}$.

In this study, it was aimed to examine the effect of 8week high-intensity interval training on speed, agility and acceleration in U19 soccer players.

\section{MATERIAL \& METHODS}

Research Group: In this study, which was conducted to determine the effect of high-intensity interval training on speed, agility, and acceleration, 11 soccer players with a mean age of $18.36 \pm 0.51$ years, a mean height of $1.77 \pm$ $0.06 \mathrm{~m}$ and a mean body weight of $71.76 \pm 6.52 \mathrm{~kg}$ were the experimental group, with a mean age of $17.55 \pm 0.69$. Year, 11 players with a mean height of $1.76 \pm 0.04 \mathrm{~m}$ and a mean body weight of $70.85 \pm 5.40 \mathrm{~kg}$ joined as the control group. This study was conducted in accordance with the non-invasive clinical research ethics committee decision of Selçuk University, Faculty of Sport Sciences, numbered 68 and dated 20.12.2018.

Soccer players of the elite U19 (16-19 years old) team from Konya Anadolu Selçukspor infrastructure team participated in the study. The soccer players participating in the study were randomly divided into 2 groups as experimental and control groups. In addition to their normal training, the experimental group participated in the High Intensity Interval training program 3 days a week for 8 weeks. The control group continued their normal training. The players participating in the research are the players who undergo training 5 days a week and play in 1 official competition.

The research was carried out in Konya Saraçoğlu facilities, which are the infrastructure team's facilities of Konya Anadolu Selçukspor. The study was applied to the pretest and post-test model. Speed, agility, and acceleration tests were applied as pre-test and post-test in the study. Before the study period, consent was obtained from the subjects for their voluntary participation in the study.

In the formation of the study group, it was determined that the subjects did not have any injury period or had not experienced any injury that would affect their performance recently. In order to determine this situation, players were passed through a health check by the club.

Height and Weight Measurements: The height of the subjects was determined by using a $0.01 \mathrm{~mm}$ precision height gage with bare feet and only shorts on top. The body weights of the subjects were determined by using Tefal Brand digital weighing device with a sensitivity of $0.01 \mathrm{gr}$, with bare feet and only shorts.

Training Program

1. Control group (11 people).

Table 1. Weekly training program of the athletes participating in the research

\begin{tabular}{|c|c|c|}
\hline Days & Durations & Training content \\
\hline Monday & - & Rest \\
\hline Tuesday & 90 minutes & $\begin{array}{l}15 \text { min warm-up run, } 15 \text { min } 5 \times 2 \text { play, } \\
15 \text { min aerobic run, } 15 \text { min passing } \\
\text { training, } 20 \text { min double goal match, } 10 \\
\text { min stretching }\end{array}$ \\
\hline Wednesday & y90 minutes & $\begin{array}{l}15 \text { min warm-up run, } 10 \text { min } 5 \times 2 \text { play, } \\
20 \text { min } 1 \times 1,2 \times 2 \text { play, } 15 \text { min wing } \\
\text { organization, } 20 \text { min half field play, } 10 \\
\text { min stretching }\end{array}$ \\
\hline Thursday & 90 minutes & 90 minutes double goal match \\
\hline Friday & 90 minutes & $\begin{array}{l}15 \text { minutes warm-up run, } 10 \text { minutes } \\
5 \times 2 \text { play, } 15 \text { minutes aerobics running, } \\
20 \text { min shooting training, } 20 \text { min half } \\
\text { field game, } 10 \text { min stretching }\end{array}$ \\
\hline Saturday & 45 minutes & $\begin{array}{l}10 \text { minutes warm-up run, } 15 \text { minutes } \\
5 \times 2 \text { play, } 10 \text { minutes } 20 \%, 10 \text { min } \\
\text { stretching }\end{array}$ \\
\hline Sunday & 90 minutes & Match \\
\hline
\end{tabular}

2. High Intensity Interval Training group (11 people).

HIIT Training Protocol: Athletes made 10 minutes of warm-up ( 5 minutes jog, 5 minutes jump)

At $90 \%$ of HR max, 90 seconds of jogging, 90 seconds of walking (rest) for 7.5 minutes, and this was accepted as 1 set. The training will be carried out on 3 sets and 2 minutes of rest is given between sets ${ }^{18}$.

In this study, the heart rate was monitored by (heart rate monitor Polar Electro Finland). The average heart rate targeted during training was applied to the training group as 188.47 beats $/ \mathrm{min}$.

One week before starting the High Intensity Interval training, both groups should have $30 \mathrm{~m}$ speed test; ProAgility agility test and $15 \mathrm{~m}$ as pre-tests. After the 8-week High Intensity Interval training is over, both groups have 30 $\mathrm{m}$ speed test; Pro-Agility agility test and $15 \mathrm{~m}$. acceleration test was measured again as a post-test.

Kadir Gökkurt, Ali Osman Kıvrak

Test Protocol

$30 \mathrm{~m}$ Speed Test: 30-meter sprint tests were applied to determine the speed of the participants. Photocells in the Newtest 300 (Finland) test battery are placed at distances of 0 and 30 meters. Participants take 5 minutes undergone a free warm-up protocol for 5 minutes in which dynamic warm-up movements are included before starting the test. The participant has 2 rights. After the first attempt, a 5minute rest period is given. After resting, athletes performed the test for the second time. The best time was recorded between the two attempts. The running time was recorded after the participant exited from the starting point when he/she felt ready and reached the end point at a 
distance of $30 \mathrm{~m}$ with the highest speed he/she could reach 19 .

Pro-Agility Test: The pro-agility test area, also known as the 20-yard running test, was determined by placing markers 5 yards $(4.57 \mathrm{~m})$ to the left and right of the baseline. Photocell gate is placed on the starting line. Repetitive passing times could be taken in this way. The participant took his/her place at the starting line before the application started. When he/she was ready, he/she first ended the test by touching the right marker, then the left marker, passing through the baseline 20 .

$15 \mathrm{~m}$. Acceleration Test: The running distance is 15 meters. Photocells are placed every 5 meters. At the starting point of the 15-meter distance ( 0 meters), the athlete took a standing position in a static standing position with one knee in front and the other in the back. Before starting to run at the starting point, the athletes were instructed to take a forward leaning stance of at least 3 seconds. No swaying or similar movements were allowed. The athletes started to run at maximum speed after waiting at least 3 seconds in this position. The best time for the 5meter interval is recorded as an indicator of acceleration and maximum running speed. Measurement results were recorded in seconds. 3 attempt rights were given for each athlete. Between each run, the athletes were provided with 3 minutes of rest 21 .

Statistical Analysis: SPSS 22.0 IBM statistical package program was used to evaluate the data obtained. Independent t-test was used to determine the difference between groups. Paired simple t test was used to compare the pre-test and post-test values. In this study, the error level was accepted as 0.05 .

The Effect of High Intensity Interval Training During Eight Week on Speed, Agility, and Acceleration in U19 Soccer Players

\section{RESULTS}

When Table 2 is examined, the average age of the subjects participating in the study as the experimental group is $18.36 \pm 0.51$ years, their average height is $1.77 \pm 0.06 \mathrm{~m}$ and their body weight is $71.76 \pm 6.52 \mathrm{~kg}$. On the other hand, the average age of the subjects in the control group was $17.55 \pm 0.69$ years, their average height was $1.76 \pm$ $0.04 \mathrm{~m}$ and their body weight was $70.85 \pm 5.40 \mathrm{~kg}$.

When Table 3 was examined, it was observed that the pre-test values of the experimental group were significantly better than the pre-test values of the control group in the comparison of the pre-test and post-test values of the athletes participating in the study between the groups $(p<0.05)$. Similarly, it is seen that the post-test values for the experimental group are significantly better than the post-test values for the control group $(p<0.05)$. When the values related to acceleration characteristics were examined, it was seen that there was no statistically significant difference between the experimental and control groups in terms of pre-test values $(p>0.05)$. On the other hand, when comparing the post-test values of the acceleration characteristics in terms of groups, it was determined that the acceleration characteristics of the experimental group was significantly better than the acceleration characteristics of the control group $(p<0.05)$. In terms of agility characteristics, there was no significant difference between the experimental and control groups in terms of both pre-test values and post-test values ( $p>0.05)$.

Table 2. Descriptive data of all participants

\begin{tabular}{|l|l|l|}
\hline Variables & $\begin{array}{l}\text { Experimental group } \\
(\mathrm{n}=11)\end{array}$ & Control group $(\mathrm{n}=11)$ \\
\hline & Mean $\pm \mathrm{SD}$ & Mean $\pm \mathrm{SD}$ \\
\hline Age (years) & $18.36 \pm 0.51$ & $17.55 \pm 0.69$ \\
\hline Height $(\mathrm{m})$ & $1.77 \pm 0.06$ & $1.76 \pm 0.04$ \\
\hline $\begin{array}{l}\text { Body weight } 71.76 \pm 6.52 \\
(\mathrm{~kg})\end{array}$ & $70.85 \pm 5.40$ \\
\hline
\end{tabular}

Table 3. Comparison of the pre-test and post-test values of the athletes participating in the study for the dependent variables in terms of groups

\begin{tabular}{|c|c|c|c|c|}
\hline Variables & Groups & Mean \pm SD & $t$ & $p$ \\
\hline \multirow{2}{*}{$\begin{array}{l}\text { Speed Pre- } \\
\text { test }\end{array}$} & $\begin{array}{l}\text { Experimental } \\
\text { group }\end{array}$ & $3.97 \pm 0.17$ & \multirow{2}{*}{2.355} & \multirow{2}{*}{$0.029^{*}$} \\
\hline & $\begin{array}{l}\text { Control } \\
\text { group }\end{array}$ & $4.12 \pm 0.13$ & & \\
\hline \multirow{2}{*}{$\begin{array}{l}\text { Speed Post- } \\
\text { test }\end{array}$} & $\begin{array}{l}\text { Experimental } \\
\text { group }\end{array}$ & $3.93 \pm 0.18$ & \multirow{2}{*}{2.344} & \multirow{2}{*}{$0.030^{*}$} \\
\hline & $\begin{array}{l}\text { Control } \\
\text { group }\end{array}$ & $4.09 \pm 0.15$ & & \\
\hline \multirow{2}{*}{$\begin{array}{l}\text { Acceleration } \\
\text { Pre-test }\end{array}$} & $\begin{array}{l}\text { Experimental } \\
\text { group }\end{array}$ & $2.16 \pm 0.09$ & \multirow{2}{*}{2.032} & \multirow{2}{*}{0.056} \\
\hline & $\begin{array}{l}\text { Control } \\
\text { group }\end{array}$ & $2.24 \pm 0.11$ & & \\
\hline \multirow{2}{*}{$\begin{array}{l}\text { Acceleration } \\
\text { Post-test }\end{array}$} & $\begin{array}{l}\text { Experimental } \\
\text { group }\end{array}$ & $2.11 \pm 0.08$ & \multirow{2}{*}{2.761} & \multirow{2}{*}{$0.012^{*}$} \\
\hline & $\begin{array}{l}\text { Control } \\
\text { group }\end{array}$ & $2.23 \pm 0.11$ & & \\
\hline \multirow{2}{*}{$\begin{array}{l}\text { Agility Pre- } \\
\text { test }\end{array}$} & $\begin{array}{l}\text { Experimental } \\
\text { group }\end{array}$ & $4.73 \pm 0.39$ & \multirow{2}{*}{1.224} & \multirow{2}{*}{0.235} \\
\hline & $\begin{array}{l}\text { Control } \\
\text { group }\end{array}$ & $4.56 \pm 0.24$ & & \\
\hline \multirow{2}{*}{$\begin{array}{l}\text { Agility Post- } \\
\text { test }\end{array}$} & $\begin{array}{l}\text { Experimental } \\
\text { group }\end{array}$ & $4.69 \pm 0.39$ & \multirow{2}{*}{1.044} & \multirow{2}{*}{0.309} \\
\hline & $\begin{array}{l}\text { Control } \\
\text { group }\end{array}$ & $4.54 \pm 0.24$ & & \\
\hline
\end{tabular}

${ }^{*} \mathrm{p}<0.05$

Table 4. Comparison of the pre-test and post-test values of the athletes participating in the study within the group

\begin{tabular}{|c|c|c|c|c|}
\hline Groups & Variables & Mean \pm SD & $\mathrm{t}$ & $p$ \\
\hline \multirow{2}{*}{$\begin{array}{l}\text { Experimental } \\
\text { group }\end{array}$} & $\begin{array}{ll}\text { Speed } & \text { Pre- } \\
\text { test } & \\
\end{array}$ & $3.97 \pm 0.17$ & \multirow{2}{*}{5.410} & \multirow{2}{*}{$0.000^{*}$} \\
\hline & $\begin{array}{l}\text { Speed Post- } \\
\text { test }\end{array}$ & $3.93 \pm 0.18$ & & \\
\hline \multirow{2}{*}{ Control group } & $\begin{array}{ll}\text { Speed } & \text { Pre- } \\
\text { test }\end{array}$ & $4.12 \pm 0.13$ & \multirow{2}{*}{1.277} & \multirow{2}{*}{0.230} \\
\hline & $\begin{array}{l}\text { Speed Post- } \\
\text { test }\end{array}$ & $4.09 \pm 0.15$ & & \\
\hline \multirow{2}{*}{$\begin{array}{l}\text { Experimental } \\
\text { group }\end{array}$} & $\begin{array}{l}\text { Acceleration } \\
\text { Pre-test }\end{array}$ & $2.16 \pm 0.09$ & \multirow{2}{*}{9.238} & \multirow{2}{*}{$0.000^{*}$} \\
\hline & $\begin{array}{l}\text { Acceleration } \\
\text { Post-test }\end{array}$ & $2.11 \pm 0.08$ & & \\
\hline \multirow[b]{2}{*}{ Control group } & $\begin{array}{l}\text { Acceleration } \\
\text { Pre-test }\end{array}$ & $2.24 \pm 0.11$ & \multirow{2}{*}{1.789} & \multirow{2}{*}{0.104} \\
\hline & $\begin{array}{l}\text { Acceleration } \\
\text { Post-test }\end{array}$ & $2.23 \pm 0.11$ & & \\
\hline \multirow[b]{2}{*}{$\begin{array}{l}\text { Experimental } \\
\text { group }\end{array}$} & Agility Pre-test & $4.73 \pm 0.39$ & \multirow[b]{2}{*}{6.206} & \multirow[b]{2}{*}{$0.000^{*}$} \\
\hline & $\begin{array}{l}\text { Agility Post- } \\
\text { test }\end{array}$ & $4.69 \pm 0.39$ & & \\
\hline \multirow[b]{2}{*}{ Control group } & Agility Pre-test & $4.56 \pm 0.24$ & \multirow[b]{2}{*}{3.155} & \multirow[b]{2}{*}{$0.010^{*}$} \\
\hline & $\begin{array}{l}\text { Agility Post- } \\
\text { test }\end{array}$ & $4.54 \pm 0.24$ & & \\
\hline
\end{tabular}


A statistically significant difference was found in the comparison of the pre-test and post-test regarding the speed and acceleration characteristics of the athletes participating in the study as an experimental group. It was seen that the post-test values were better in this comparison $(p<0.05)$. On the other hand, it was determined that there was no statistically significant difference in the comparison of the pre-test and post-test regarding the speed and acceleration characteristics of the control group ( $p>0.05)$. In terms of agility characteristics, it was observed that there was a statistically significant difference in both the pre-test and post-test comparison of the experimental group and the pre-test-post-test comparison of the control group $(p<0.05)$. In terms of agility, an improvement of 0.008 was observed in the experimental group, while an improvement of 0.004 was observed in the control group.

\section{DISCUSSION}

In this study, which was conducted to examine the effect of high-intensity interval training on speed, agility and acceleration performance, it was observed that the posttest values were better in the comparison of the pre-test and post-test regarding the speed and acceleration characteristics of the experimental group athletes $(p<0.05)$. In terms of agility, an improvement of 0.008 was observed in the experimental group, while an improvement of 0.004 was observed in the control group $(p<0.05)$.

Another motor characteristic needed in soccer is speed. Because in soccer, there are movements that require reaction speed, positive and negative acceleration, rapidity, speed, movement speed, high action movements and repetitive speed performance ${ }^{8}$. In soccer, if a player can benefit himself in any position in a short time, he is considered a fast soccer player. The speed performance of soccer players is not similar to the speed performance of a $100 \mathrm{~m}$ sprint runner. Because the sprint technique used by the athlete in soccer is different and speed training specific to soccer is used in developing speed 22 .

In a study examining the effects of high-intensity aerobic training and speed endurance training on basic physiological performance in football, it was reported that speed endurance training improved football-specific endurance by $6 \%$ and repetitive sprinting ability by about $2 \% 23$. In a study examining the effects of high-intensity training with own body weight for 6 weeks on flexibility and anaerobic capacity, significant increases were found in flexibility, body weight and anaerobic power values of sedentary women who did high-intensity interval training 24 . Krustrup et al. ${ }^{25}$, in a study conducted with the idea that intensive interval training increases muscle blood flow and oxygen consumption, it was reported that high intensity exercise increased muscle oxygen use, blood flow and vascular conductivity in the first phase. In a study examining the effects of moderate endurance and highintensity interval training on anaerobic capacity and VO2 max, medium-intensity aerobic training increases maximal aerobic power but does not alter anaerobic capacity. However, high intensity interval training can improve both energy systems 26

The Effect of High Intensity Interval Training During
Eight Week on Speed, Agility, and Acceleration in U19 Soccer Players

In a study conducted by Günay et al. ${ }^{27}$ on the effect of two different types of interval training programs on some physiological parameters, it was found that the first type of high-intensity interval training caused significant increases compared to the second type of high-intensity interval training and that the changes in both training groups were similar. In a study examining the effect of high-intensity interval training on speed, agility, and aerobic performances of football players for 8 weeks, it was reported that there are significant increases among 30 meters speed test values ${ }^{28}$. Sperlich et al. ${ }^{29}$, in a study in which they examined the effects of 5 -week high-intensity interval training and intensity training in 14-year-old soccer players, reported that there was a significant difference in the $30 \mathrm{~m}$ sprint test mean values of soccer players. lacono et al. ${ }^{30}$, stated in their study on elite handball players that there was a significant difference in the average values of the 20-meter running test. Howard and Stavrianeas 31 , in a study in which the effect of high-intensity interval training for 10 weeks on the increase in performance during the season was examined in soccer players, found that there was a significant difference in the average values of the 40 yard $(36.58 \mathrm{~m})$ speed running test. Wong et al. ${ }^{32}$, in a study examining the effect of 8-week high-intensity interval training on explosive strength and aerobic capacity in professional soccer players, reported that there was a significant difference between the 30-meter speed running test average values. Siegler et al. ${ }^{33}$, in a study that examined soccer-specific strength endurance of 10 -week high-intensity training in soccer players, reported that there was a significant difference between the 20-meter speed running test values of soccer players. Dupont et al. ${ }^{34}$, in a study examining the effect of high intensity interval training on in-season performance of soccer players, reported that there was a statistically significant difference between the 40-meter speed running test values of soccer players. In these studies, the effect of high-intensity interval training on speed was examined, and results are similar to our study.

Bravo et al. ${ }^{35}$, examined the effect of high intensity interval training and repetitive sprint training on aerobic performance. For 12 weeks, 2 days a week, the high intensity interval training group performed 4 minutes $\times 4$ sets with a $90-95 \%$ of maximum heart rate, while the repetitive sprint training group performed a total of $40 \mathrm{~m}$ distance as 3 sets $\times 6$ repetitions by $100 \%$ on load-on sprint training. Both training groups showed a close percentage improvement in Max VO2 values (Y.Ş.I. AG = $3 \%$, TSAG $=6 \%$ ). In a study investigating the effect of intensive interval training method on aerobic and anaerobic power in young football players aged 14-16 years, it was reported that there was a significant increase in the anaerobic power of athletes 36 .

In a study performed on elite handball player by lacono et al. ${ }^{30}$, it is reported that there was a significant difference in the agility test average values of the high-intensity interval training group. Akılveren ${ }^{28}$, reported that there was a statistically significant difference between 
the average values of agility in a study examining the effect of high-intensity interval training on speed, agility, and aerobic performances of football players for 8 weeks. In these studies, the effect of high-intensity interval training on agility has been examined, and the results are similar to our research.

In a study conducted on elite handball players by lacono et al. ${ }^{30}$, it was reported that there was a significant difference in the 10-meter running test average values of the high-intensity interval training group. Wong et al. ${ }^{32}$, in a study investigating the effect of 8-week high-intensity interval training on explosive strength and aerobic capacity in professional soccer players, reported that there was a statistically significant difference between the 10-meter running test mean values of soccer players. In these studies, the effect of high-intensity interval training on acceleration was examined, and they are similar to our study.

Howard and Stavrianeas 31 , in a study examining the effect of high-intensity interval training on seasonal performance in soccer players, reported that there was no significant difference between the average values of the agility test. Fernandez-Fernandez et al. ${ }^{37}$, in a study examining the effects of high-intensity interval training and repetitive sprint training on performance variables, reported that there was no statistically significant difference between the average values of the 20 -meter speed running test. These studies differed from our study.

\section{CONCLUSION}

It has been observed that 8-week high-intensity interval training has a positive effect on the speed and acceleration of soccer players. High-intensity interval training in soccer increases the speed, agility, and acceleration performance of soccer players, but it is significant in the experimental and control groups in terms of agility average values, and the reason for this is that the high-intensity interval training characteristics are not reversed runs, so it is thought that the improvement in agility performance is due to this. While creating the annual training plan, it is thought that the inclusion of direction-changing running in the content of high-intensity interval training will positively affect the performances of the athletes during the season.

Acknowledgments: This study was written by abridging Kadir GÖKKURT's Selçuk University Institute of Health Sciences, Department of Coaching Education master's thesis. The authors sincerely thank the subjects, who participated in this study and contributed to the realization of this study. This research received no funding. Kadir Gökkurt, Ali Osman Kıvrak

\section{REFERENCES}

1. Issurin VB. New horizons for the methodology and physiology of training periodization. Sport Med, 2010; 40(3): 189-206. https://doi.org/10.2165/11319770-00000000000000

2. Wang L, Gao W, Xiong K, Liu N, Wang B. The effects of an early return to training on the bone tendon junction post acute micro injury healing. journal of sports science medicine, 2012; 11(2): 238-244.

3. Reilly T. Science and soccer. Ed: E \& FN SPON. London, Chapman \& Hall, 1996; 25-64.
4. Reilly T. Science developing strength speed and endurance. London, United Kingdom: Routledge, 2007.

5. Bangsbo J, Mohr M, Krustrup P. Physical and metabolic demands of training and match-play in the elite football player. J. Sports Sci, 2006; 24(7): 665-674. https://doi.org/10.1080/02640410500482529

6. Hoff J, Wisloff U, Engen IC, Kemi OJ, Helgerud J. Soccer specific aerobic endurance training. Br J Sports Med, 2002; 36(3): 218-221. http://dx.doi.org/10.1136/bjsm.36.3.218

7. Hoff J. Training and testing physical capacities for elite soccer players. Journal Sports Science, 2005; 23(6): 573582. https://doi.org/10.1080/02640410400021252

8. Eniseler N. Soccer training in the light of science. Manisa, Birleşik printing press, 2010; 16-242.

9. Helgerud J, Engen LC, Wisloff U, Hoff J. Aerobic endurance training improves soccer performance. Med Sci Sports Exerc, 2001; 33(11): 1925-1931. https://doi.org/10.1097/00005768-200111000-00019

10. Reilly T. Energetics of high intensity exercise (soccer) with particular reference to fatigue. Journal of Sports Sciences, 1997;15(3):257-263.

https://doi.org/10.1080/026404197367263

11. Sevim Y. Training information. Nobel broadcast distribution, Ankara, 2002; 65-72.

12. Bayati M, Farzad B, Gharakhnlou R, Alınejad HA. A practical model of low-volume high intensity interval training induces performance and metabolic adaptations that resemble 'allout' sprint interval training. Journal of Sports Science and Medicine, 2011; 10(3): 571-576.

13. Açıkada C, Ergen E. Science and sports. Büro-tek offset, Ankara, 1990.

14. Reilly T, Williams AM. Introduction to science and soccer. In Science and Soccer, 2003; 1-6.

15. Hazır T, Mahir ÖF, Açıkada C. Relationship between agility and body composition, anaerobic power in young soccer players. Hacettepe J. of Sport Sciences, 2009; 21(4): 146153.

16. Murphy A, Lockie R, Coutts J. Kinematic determinants of early acceleration in field sport athletes. J Sport Sci Med, 2003; 2(4): 144-150.

17. Karabük S, Aşçı A, Altay F, Cengiz R, Hazır T, Bulca $Y$. Soccer education under the age of 14, Ed: Karabük $S$, Tüfav Publications, Ankara, 2008.

18. Arazi $H$, Keihaniyan $A$, Eatemady Boroujeni $A$, Oftade $A$, Takhsha S, Asadi A, Ramirez-Campillo R. Effect of heart rate vs. speed-based high intensit interval traing on aerobic and aneorobic capacity moffe male soccer players. Sports, 2017; 5(57): 1-8. https://doi.org/10.3390/sports5030057

19. Svensson M, Drust B. Testing soccer players. Journal of Sports Sciences, 2005; 23(6): 601-618. https://doi.org/10.1080/02640410400021294

20. Bayraktar I. Relationships between elite boxers' agility, speed, reaction and vertical jumping abilities. Akademik Bakış Journal, 2013; 35: 1-8.

21. Bloomfield J, Polman R, O'Donoghue P, McNaughton L. Effective speed and agility conditioning methodology for random Intermittent dynamictype sports. J Strength Cond Res, 2007; 21(4): 1093-1100.

22. Karatosun $\mathrm{H}$. Physical performance improvement in soccer. Altıntuğ Offset, Isparta, 2012.

23. laia FM, Ermanno R, Bangsbo J. High-intensity training in football. International Journal of Sports Physiology and Performance, 2009; 291-306. https://doi.org/10.1123/ijspp.4.3.291

24. Baynaz K, Acar K, Çinibulak E, Atasoy T, Mor A, Pehlivan B, Arslanoğlu $E$. The effect of high intensity interval training on flexibility and anaerobic power. Journal of Human Sciences, 2017; 14(4): 4088-4096. https://doi.org/10.14687/jhs.v14i4.5062

25. Krustrup P, Hellsten Y, Bangsbo J. Intense interval training 
enhances human skeletal muscle oxygen uptake in the initial phase of dynamic exercise at high but not at low intensities. The Journal of Physiology, 2004; 559(1): 335-345. https://doi.org/10.1113/jphysiol.2004.062232

26. Tabata I, Nishimura K, Kouzaki M, Hirai Y, Ogita F, Miyachi $\mathrm{M}$, Yamamoto K. "Effects of moderate- intensity endurance and high-intensity intermittent training on anaerobic capacity and VO2max", Med Sci Sports Exerc, 1996; 28(10): 13271330. https://doi.org/10.1097/00005768-199610000-00018

27. Günay M, Tamer K, Cicioğlu I, Çevik C. The effect of two different types of interval moment training programs on some physiological parameters. Ege University Journal of Sports Medicine, 2000; 35(4): 139-146.

28. Akılveren E. Examination on the effect of high-intensity interval training and repeated sprint training on aerobic performance in football (Master thesis). Akdeniz University Institute of Health Sciences; 2018; Antalya.

29. Sperlich B, De Marées M, Koehler K, Linville J, Holmberg $\mathrm{HC}$, Mester J. Effects of 5 weeks of high-intensity interval training vs. volume training in 14-year-old soccer players. The Journal of Strength Conditioning Research, 2011; 25(5): 1271-1278. https://doi.org/10.1519/JSC.0b013e3181d67c38

30. lacono AD, Eliakim A, Meckel Y. Improving fitness of elite handball players: small-sided games vs. high-intensity intermittent training. The Journal of Strength \& Conditioning Research, 2015; 29(3): 835-843. https://doi.org/10.1519/JSC.0000000000000686

31. Howard N, Stavrianeas S. In-season high-intensity interval training improves conditioning in high school soccer players. International Journal of Exercise Science, 2017; 10(5): 713-
720.

32. Wong PL, Chaouachi A, Chamari K, Dellal A, Wisloff U. Effect of preseason concurrent muscular strength and highintensity interval training in professional soccer players. The Journal of Strength Conditioning Research, 2010; 24(3): 653-660. https://doi.org/10.1519/JSC.0b013e3181aa36a2

33. Siegler J, Gaskıll S, Ruby B. Changes evaluated in soccerspecific power endurance either with or without a 10-week, in-season, intermittent, high-intensity training protocol. The Journal of Strength Conditioning Research, 2003; 17(2): 379-387.

34. Dupont G, Akakpo K, Berthoin S. The effect of in-season, high-intensity interval training in soccer players. The Journal of Strength Conditioning Research, 2004; 18(3): 584-589.

35. Bravo DF, Impellizzeri FM, Rampinini E, Castagna C, Bishop $D$, Wisloff U. Sprint vs. interval training in football. Int J Sports Med, 2008; 29(8): 668-674. https://doi.org/10.1055/s2007-989371

36. Altın M, Kaya $\mathrm{Y}$. The Effects of intensive interval training method on aerobic and anaerobic power in the junior, male football players of 14-16 age group (Master thesis). Selçuk University, Institute of Health Sciences; 1998; Konya.

37. Fernandez-Fernandez J, Zimek R, Wiewelhove T, Ferrauti A. High-intensity interval training vs. repeated-sprint training in tennis. The Journal of Strength \& Conditioning Research, 2012; 26(1):

53-62.

https://doi.org/10.1519/JSC.0b013e318220b4ff 